\title{
Series Foreword
}

$\mathrm{T}$ He STARTLING AND MOVING events that swept from China to Eastern Europe to Latin America and South Africa at the end of the I980s, followed closely by similar events and the subsequent dissolution of what used to be the Soviet Union, formed one of those great historic occasions when calls for freedom, rights, and democracy echoed through political upheaval. A clear-eyed look at any of those conjunctions - in 1776 and 1789 , in 1848 and 1918 , as well as in I989-reminds us that freedom, liberty, rights, and democracy are words into which many different and conflicting hopes have been read. The language of freedom-or liberty, which is interchangeable with freedom most of the time-is inherently difficult. It carried vastly different meanings in the classical world and in medieval Europe from those of modern understanding, though thinkers in later ages sometimes eagerly assimilated the older meanings to their own circumstances and purposes.

A new kind of freedom, which we have here called modern, gradually disentangles itself from old contexts in Europe, beginning first in England in the early seventeenth century and then, with many confusions, denials, reversals, and cross-purposes, elsewhere in Europe and the world. A large-scale history of this modern, conceptually distinct, idea of freedom is now beyond the ambition of any one scholar, however learned. This collaborative enterprise, tentative though it must be, is an effort to fill the gap.

We could not take into account all the varied meanings that freedom and liberty have carried in the modern world. We have, for example, ruled out extended attention to what some political philosophers have called "positive freedom," in the sense of self-realization of the individual; nor could we, even in a series as large as this, cope with the enormous implications of the four freedoms invoked by Franklin D. Roosevelt in I94I. Freedom of speech and freedom of the 
press will have their place in the narrative that follows, certainly, but not the boundless calls for freedom from want and freedom from fear.

We use freedom in the traditional and restricted sense of civil and political liberty - freedom of religion, freedom of speech and assembly, freedom of the individual from arbitrary and capricious authority over persons or property, freedom to produce and to exchange goods and services, and the freedom to take part in the political process that shapes people's destiny. In no major part of the world over the past few years have aspirations for those freedoms not been at least powerfully expressed; and in most places where they did not exist, strong measures have been taken - not always successfully - to attain them.

The history we trace was not a steady march toward the present or the fulfillment of some cosmic necessity. Modern freedom had its roots in specific circumstances in early modern Europe, despite the unpromising and even hostile characteristics of the larger society and culture. From these narrow and often selfishly motivated beginnings, modern freedom came to be realized in later times, constrained by old traditions and institutions hard to move, and driven by ambition as well as idealism: everywhere the growth of freedom has been sui generis. But to understand these unique developments fully, we must first try to see them against the making of modern freedom as a whole.

The Making of Modern Freedom grows out of a continuing series of conferences and institutes held at the Center for the History of Freedom at Washington University in St. Louis. Professor J. H. Hexter was the founder and, for three years, the resident gadfly of the Center. His contribution is gratefully recalled by all his colleagues.

R.W.D. 